\title{
Hyperkinetic circulatory disorder after closure of persistent ductus arteriosus
}

\author{
Knut Rasmussen and Ole Storstein \\ From Medical Department B, University Hospital, Rikshospitalet, Oslo, Norway
}

Two young women developed symptoms and signs of progressive heart disease several years after successful closure of a persistent ductus arteriosus. The patients had strikingly similar abnormalities of physiognomy and hypertrichosis. Right heart catheterization disclosed a hyperkinetic circulation with extremely high resting cardiac output and a very low vascular resistance. One patient was investigated further with exercise and $\beta$-adrenergic blockade; none of the procedures had any influence on the condition. The hyperkinetic state should probably be classified as idiopathic, but differs from most previous descriptions of this syndrome both in its severity and in that a primary disturbance of vascular autoregulation with secondary heart involvement seems to be present.

Persistent ductus arteriosus is commonly regarded as a purely mechanical disorder which only requires adequate closure for complete normalization of heart volume and prognosis. The common rapid normalization of heart volume and functional capacity is well documented (Ekström, 1952; Strauss, Abrams, and Robinson, 1958). This report describes two young women with unequivocal signs of persistent circulatory malfunction several years after successful closure of a persistent ductus.

\section{Case reports}

Case I A woman, born in 1950. There is no history of relevant familial disease. Both parents and two brothers have normal hair growth and a normal appearance. At birth she showed several peculiarities, of which the most outstanding were an extra finger, a peculiar physiognomy, hirsutism, and cutaneous oedema. A diagnosis of Hurler's syndrome was considered. However, she developed normally in most respects. She was admitted to hospital several times during childhood because of the remarkable hair growth. Heart disease was suggested at the age of 9 months, when a systolic murmur was described. In 1956 a continuous murmur over the second left interspace was heard. Right heart catheterization was performed (Table). The presence of a small left-to-right shunt to the pulmonary artery was confirmed. At the age of ro she was operated on with ligation of a persistent ductus arteriosus, $15 \mathrm{~mm}$ broad.

Before the operation and during the first years

Received 3I August 197 I. afterwards she had no symptoms of heart disease. When I4 years old, however, she developed for the first time pitting oedema in both legs and slight dyspnoea on effort. Since then these symptoms have progressed gradually. She was therefore readmitted to the department in 1965 . Her face was then found to be round with prognathism, thick protruding lips, flat nose, and some degree of hypertelorism. The hair boundaries were low in the front and at the cheeks, and she had soft black lanugo-like hairs on most of the face, on the extremities, and on the back. Her pubic hair distribution was female. Pitting oedema was found to the middle of the calves, but other signs of congestive heart failure were not disclosed. The blood pressure was normal both in arms and legs. A systolic murmur, grade $3 / 6$, was heard over the second and third left interspace and over the apex. The second heart sound was intermittently split in the second left interspace, and at the apex a third heart sound was heard (Fig. I). The pulse rate during the stay in hospital varied between 70 and 85 . Height and weight were normal and there were no clinical signs of hyperthyroidism. The electrocardiogram was only slightly abnormal (Fig. I), but $x$-ray of the heart showed definite pathology (Fig. 2). Another right heart catheterization with hydrogen curves showed no signs of residual left-to-right shunt. The systolic pressures in the right ventricle and pulmonary artery were slightly raised and the cardiac output was high. Pulmonary arteriolar resistance and oxygen consumption were normal, but the AV oxygen difference was abnormally small. The investigation was performed after pretreatment with barbiturates, but she was nevertheless somewhat anxious during the procedure. 
TABLE Pre-and postoperative right heart catheterization data

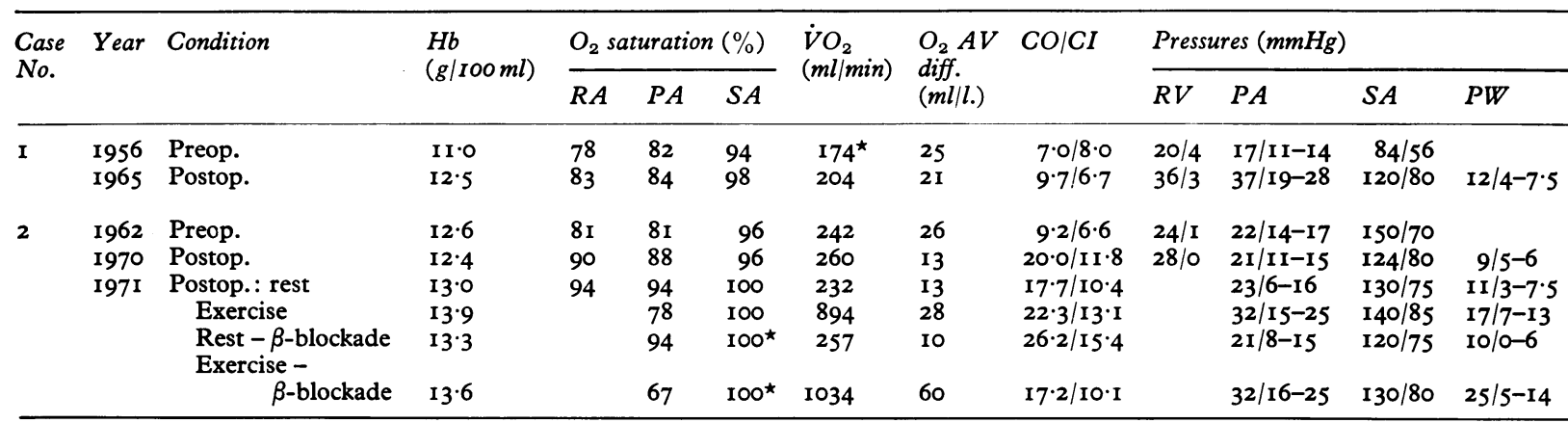

RA, right atrium; PA, pulmonary artery; SA, systemic artery; RV, right ventricle; $P W$, pulmonary artery wedge position; CO, cardiac output (1./min); CI, cardiac index $\left(1 . / \mathrm{min} / \mathrm{m}^{2}\right) ; \mathrm{SV}$, stroke volume (ml/beat); SVI, stroke volume index $\left(\mathrm{ml} / \mathrm{beat} / \mathrm{m}^{2}\right) ; \mathrm{HR}$, heart rate.

* Assumed.

FIG. I Case I. Postoperative I2-lead electrocardiogram and phonocardiogram in 1965.

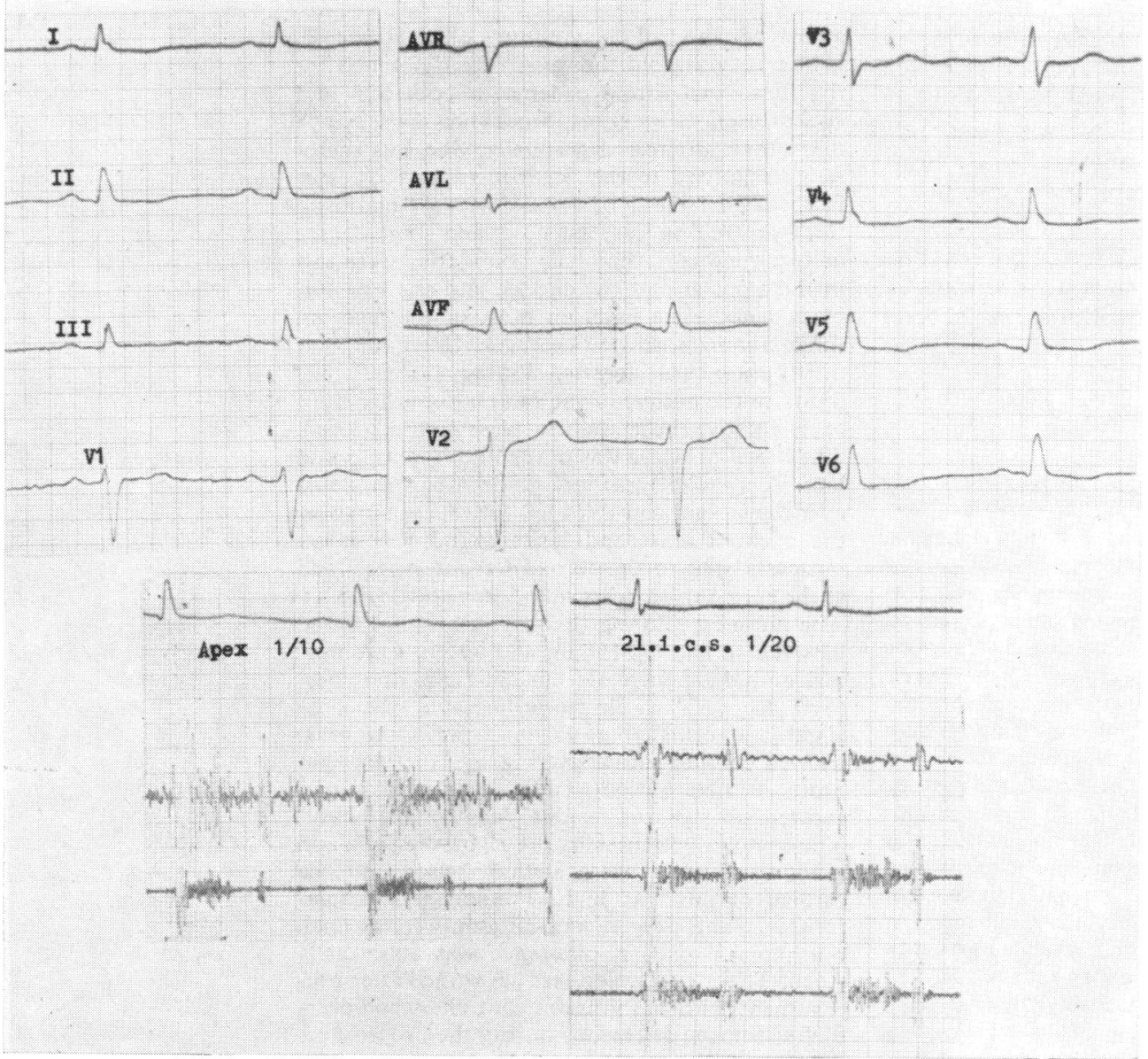




\begin{tabular}{llcc}
\hline $\begin{array}{l}\text { Pulm. art. } \\
\text { resist. } \\
\left(\text { dyne sec } / \mathrm{cm}^{5}\right)\end{array}$ & $\begin{array}{l}\text { System. art. } \\
\text { resist. } \\
\left(\text { dyne sec } / \mathrm{cm}^{5}\right)\end{array}$ & $\begin{array}{l}\text { Heart rate } \\
\text { (beats/min) }\end{array}$ & SV/SVI \\
\hline & 690 & & \\
120 & 750 & 90 & $78 / 54$ \\
& 825 & $100-110$ & $92 / 66$ \\
36 & 380 & $90-100$ & $220 / 130$ \\
41 & 410 & 83 & $208 / 122$ \\
32 & 359 & 120 & $186 / 109$ \\
27 & 290 & 85 & $291 / 171$ \\
37 & 581 & 110 & $156 / 92$ \\
\hline
\end{tabular}

Repeated urinary hormone determinations including corticosteroids, I7 ketosteroids, androgens, and gonadotropins were all normal. No biochemical signs of hyperthyroidism, amyloidosis, rheumatic, or other systemic disease were disclosed. Antistreptolysin titre and serum proteins were normal.

After the stay in hospital she was followed for two years and then lost for control. During this period a slight progression of both dyspnoea and oedema occurred. The latter did not respond to digitoxin and thiazides, but better to small doses of ethacrynic acid. Menarche had not occurred until 1967, but mammary development had started. She had finished 7 years of public school, but seemed to have poorer intellectual capacity than her relatives.

Case 2 A woman, born in 1949. No endocrine, heart, or other relevant disease are known in the family. Her parents, sister, and brother are all healthy. At the age of 13 , she developed for the first time, intermittent oedema at both ankles and a moderate dyspnoea on effort. She was first admitted to hospital shortly afterwards because of her extensive black hair growth, predominant over the cheeks, front, and distally at the extremities. The pubic hair distribution was female. A continuous machinery murmur was heard in the second and third left interspace at the time of admission. The presence of a persistent ductus arteriosus was shown through right heart catheterization, during which the catheter passed from the pulmonary artery to the aorta (Table). The oxygen saturation, however, did not increase significantly in the pulmonary artery. The pressures were normal, oxygen consumption was in the upper normal range, AV oxygen difference was abnormally small, and the cardiac output correspondingly increased. Urinary secretion of corticosteroids and 17-ketosteroids, both before and after ACTH stimulation, gonadotrophic hormones, and androgens, were all normal for the age.

In 1963, a persistent ductus arteriosus with a

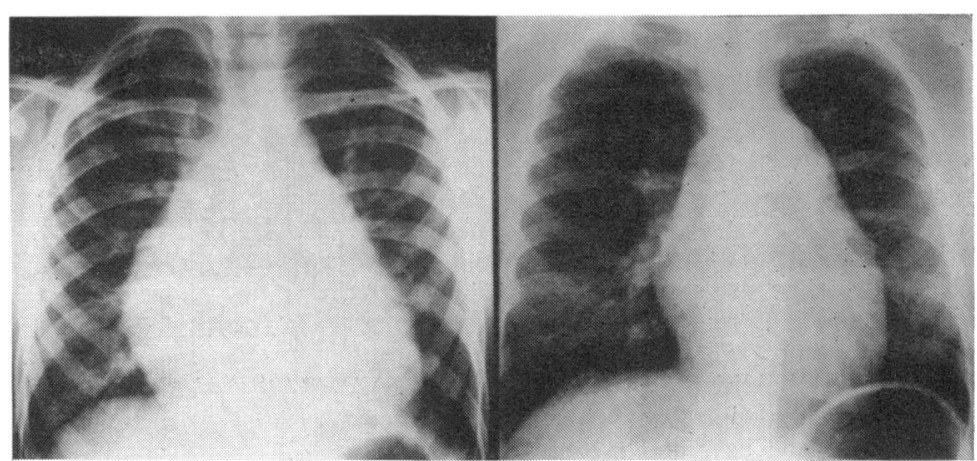

FIG. 2 Case I. Left: preoperative frontal chest x-ray (I960). Right: postoperative (1965). The latter shows enlargement of the left ventricle and a widened pulmonary conus. Volume $555 \mathrm{ml} / \mathrm{m}^{2}$.

diameter of $7 \mathrm{~mm}$ was ligated. Afterwards, all her symptoms subsided for some years. She developed normally with normal female sex characteristics and menstrual cycles. During 1968, however, she once more developed intermittent oedema and breathlessness during the night, relieved by sitting up. She became exhausted after a day of light physical work. She was therefore readmitted in 1970. Again the hirsutism was obvious, localized as previously. She had a peculiar physiognomy

FIG. 3 Case 2. The hair on the lower face has partly been shaven off.

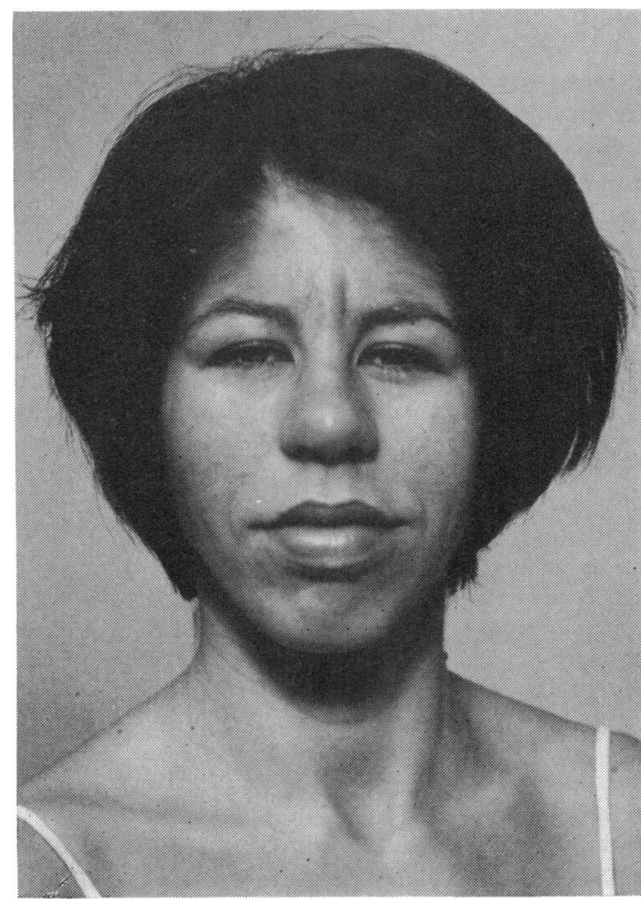


with protruding mid-face, open mouth, and thick lips (Fig. 3). Intellectually she gave a poor impression, but she had completed 7 years of public school: Her gait was wagging and jerky. The skin was warm with dilated vęins, but she showed no other signs of hyperthyroidism or other endocrine disorder. During rest the arteries on the neck were pulsating heavily and the head was nodding. The apical heart impulse was found in the $4^{\text {th }}$ and 5 th interspace $10 \mathrm{~cm}$ from the midline. A blowing systolic murmur, strength $3 / 6$, was heard, with maximum in the third left interspace (Fig. 4). The second heart sound was slightly accentuated to the left of the base and inconstantly split. A fourth heart sound was heard along the left sternal border. The blood pressure was normal. Slight oedema was found at the ankles. Electrocardiogram showed signs of left ventricular hypertrophy (Fig. 4). $X$-ray disclosed an enlarged heart (Fig. 5). No signs of endocrine or systemic disease were found, except for a transiently raised antistreptolysin titre and a transient leucopenia. Routine urinary and blood analyses were normal except for a moderate sideropenic anaemia which responded adequately to oral iron supplements. During her stay in the department she had resting heart rates between 80 and 95 a minute. Chromosome analysis and sex chromatin were normal. Gynaecological examination showed normal internal female genitalia. Repeated hormone determinations including serum $\mathrm{LH}$ and testosterone, urinary androgens, and catecholamines were all normal. $X$-ray of the skeletal system including the skull was normal. Another right heart catheterization was performed (Table). Again the pressures were normal and the cardiac output distinctly raised with an extremely low AV oxygen difference. Hydrogen curves showed no signs of left-to-right shunt; this was also confirmed by contrast injection to the aortic arch.

During the last year she has used diuretics, iron, and digitoxin, and has improved slightly. She is still able to perform her daily work.

In March I97I she was readmitted for reinvestigation. Venous occlusion plethysmography was done on one leg. The resting flow was calculated to $18.3 \mathrm{ml} / \mathrm{min}$ per $100 \mathrm{ml}$ tissue (normal 2-6). Post-occlusion flow was only slightly higher than normal. After intravenous injection of $20 \mathrm{mg}$ practolol she spontaneously remarked that the heart beats were more feeble than usual. The recorded resting flow, however, increased slightly but steadily through the first 20 minutes after the injection to $25 \mathrm{ml} / \mathrm{min}$ per $100 \mathrm{ml}$.

A third right heart catheterization was undertaken (Table). After the resting values had been recorded, she exercised $250 \mathrm{kpm} / \mathrm{min}$ for 14 minutes in the supine position. Thereafter $20 \mathrm{mg}$ practolol was injected intravenously and new resting data were recorded after 20 to 30 minutes. Then an identical exercise test was performed. She tolerated the tests well. As shown in the Table, the resting cardiac output was extremely high and, contrary to what had been expected, it did not decrease after $\beta$-adrenergic blockade. It should be emphasized that the errors of cardiac

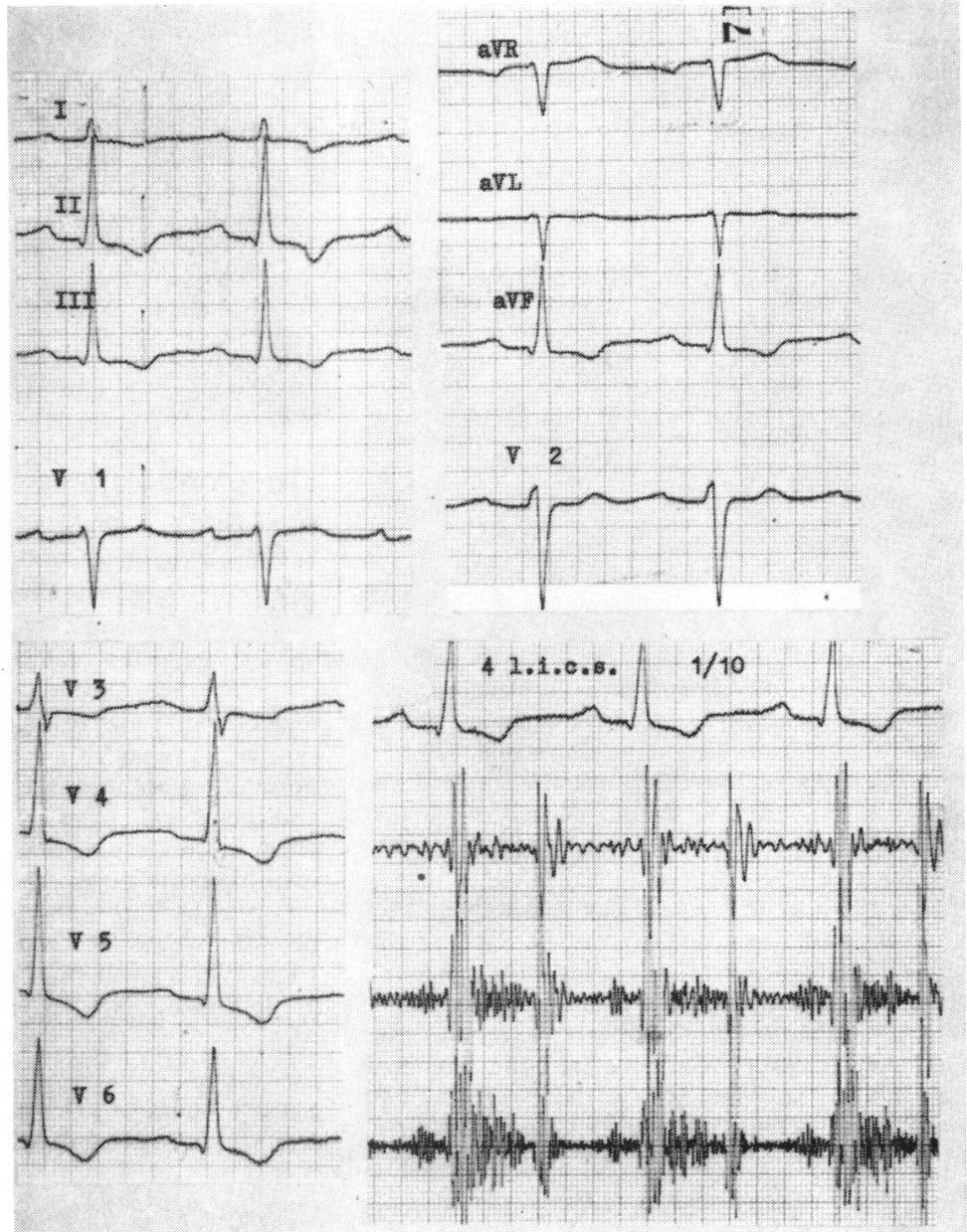

FI . 4 Case 2. Postoperative I2-lead electrocardiogram and phonocardiogram (1970).

output measurements with this method are large when the AV oxygen differences are low. The measurements made during exercise are therefore the most reliable. Nevertheless, it seemed remarkable that both in terms of cardiac output and plethysmography the resting flow increased after 'cardioselective' $\beta$-adrenergic blockade. The ability to increase the cardiac output from the resting value was practically absent; the increase in oxygen transport is solely accounted for by an increased AV oxygen extraction. The ability to maintain the stroke volume during exercise seems to be significantly impaired by $\beta$-adrenergic blockade. The pressure recordings were all normal and the calculated systemic arteriolar resistance extremely low.

\section{Discussion}

The most conspicuous features of these two patients are as follows. 
I) An abnormal clinical course after technically successful ligation of a persistent ductus. After an asymptomatic period increasing symptoms and signs of heart disease developed. $X$-ray of the heart showed progressive cardiomegaly. Electrocardiogram was abnormal in Case 2, and slightly so in Case I.

2) At right heart catheterization a hyperkinetic circulation, not suspected clinically, was found. In Case 2 the cardiac output was essentially uninfluenced by exercise and $\beta$ adrenergic blockade.

3) The patients had a similar physiognomy and advanced hypertrichosis, strikingly abnormal when compared to the Norwegian population and the respective families. Both patients had primarily been in hospital because of their extensive hair growth.

The most frequent causes of a lack of improvement after closure of a persistent ductus are recanalization of the ductus (Helsingen, Husom, and Efskind, 1958), residual congenital heart disease, bacterial endocarditis, and coexistent rheumatic heart disease (Boone and Rosemond, 1960). Pericarditis and 'postpericardiotomy syndrome' may give rise to a prolonged postoperative course. In our opinion these possibilities have been ruled out in the present cases. Of about 700 patients operated on in this hospital since 1946 for persistent ductus, I2 patients had residual symptoms or signs of heart disease at followup (Helsingen et al., 1958; Trippestad and Efskind, 1972). In all but the two patients this lack of improvement could be adequately explained from the above-mentioned possibilities. Thus, the course in these patients is clearly atypical and not an expression of a general tendency in persistent ductus.

Two other types of residual haemodynamic abnormalities after apparently successful closure of left-to-right shunts have been described. Lueker, Vogel, and Blount (1969) observed persistently raised pulmonary artery pressure, with lowered cardiac output due to an abnormal pulmonary vascular bed in 12 patients several years after closure of a persistent ductus arteriosus. Secondly, myocardial abnormalities with reduced left ventricular performance have been described after closure of atrial (Davies et al., 1970) and ventricular (Bloomfield, I964) septal defects. Evidence that a persistent ductus also may impair myocardial function has been provided by Jarmakani et al. (1969) and Mason et al. (1968). However, these conditions agree neither clinically nor haemodynamically with the presently described low resistance - low pressure hyperkinetic syndrome.

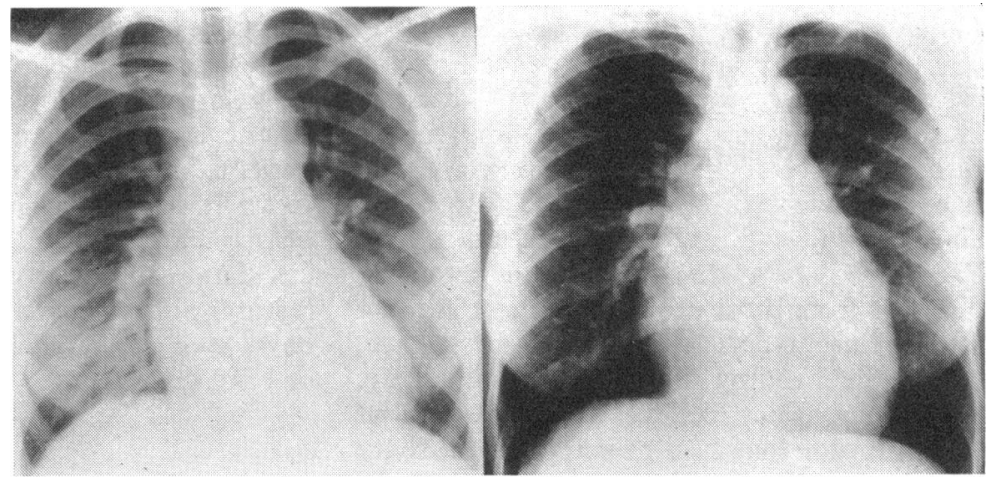

FIG. 5 Case 2. Left: preoperative frontal chest film (1963). Right: postoperative (1970). The latter shows a generally enlarged heart (volume $815 \mathrm{ml} / \mathrm{m}^{2}$ ), with probable dominance of the right ventricle.

Well-known causes of hyperkinesis such as localized pulmonary or systemic AV shunts, beriberi, hyperthyroidism, phaeochromocytoma, Paget's disease, liver cirrhosis, pregnancy, hereditary teleangiectases, emphysema, and first-degree arterial hypertension can be excluded with great confidence in these patients. Only the first two of the conditions mentioned might possibly give rise to cardiac outputs as high as reported here. During the first four catheterizations the moderate anaemia (Table) may have contributed to the hyperkinesis, but this would only serve to compensate for a decreased venous oxygen content, which, however, was high. Correction of the anaemia in Case 2 did not reduce cardiac output. Anxiety may have been another contributing factor, but both patients had only moderate tachycardia during the investigation. Thus the condition should probably be classified as an idiopathic hyperkinetic state.

An increased cardiac output may be caused by an increased peripheral demand for oxygen, a defective oxygen transport from blood to tissues, defective regulation of the peripheral vascular tone, or by primary hyperactivity of the heart. The oxygen consumption was normal in our patients. No positive evidence of a defective oxygen transport, for instance in terms of an abnormal oxygen dissociation curve, is available. Therefore, the cause of hyperkinesis in the present cases should be sought in the vascular bed and the heart.

These two possibilities are reflected in the two types of idiopathic hyperkinetic syndromes which have previously been described. 
Holmgren et al. (1957) described a group of subjects with normal circulatory pressures and raised cardiac output under the heading 'vasoregulatory asthenia', thus implying a primary vascular genesis of the condition. American workers (Gorlin, 1962; Brachfeld and Gorlin, 1960; Frohlich, Dustan, and Page, 1966) have described similar patients, differing from those of Holmgren et al. in that several were hypertensive or prehypertensive, under the heading 'idiopathic hyperkinetic syndrome'. They believe that the cause of the syndrome may be a primary hyperactivity of the heart. The improvement of the condition caused by propranolol (Frohlich, Tarazi, and Dustan, 1969) led to the concept of increased cardiac $\beta$-adrenergic responsiveness. The present two patients do not conform with any of these pictures, because of the more advanced hyperkinesis and the more severe symptoms and signs of circulatory disease.

Guyton, Granger, and Coleman (197I) have recently stressed the importance of autoregulation of the total circulation. From this concept, a primary hyperactivity of the heart with an increase in cardiac output would cause an increase in the vascular resistance. On the other hand, a primary decrease in vascular tone might induce an entirely secondary cardiac hyperactivity. The latter situation seems to be present in our patients, with a constant extreme vasodilatation and an almost fixed cardiac output, probably close to the maximal performance of the left ventricle. While the peripheral vascular bed is the limiting factor of circulation in normal subjects, the limiting factors in these patients may be the heart. The symptoms and signs of heart disease are then probably only evidence of this secondary hyperactivity.

This concept is further supported by the complete lack of effect of an amount of practolol sufficient to give almost complete $\beta$ adrenergic blockade. The only significant effect of practolol, the decreased ability to maintain the raised stroke volume during exercise, is then not an improvement but rather an impairment of a compensating mechanism. Because of the high degree of cardioselectivity (Dunlop and Shanks, 1968) practolol is a better drug than propranolol for differentiating cardiac effects from vascular. The observed increase of extremity flow and cardiac output after administration of practolol may possibly be a reflection of the intrinsic sympathicomimetic activity of the drug.

In both patients the oedema was restricted to the legs, was somewhat intermittent, and extremely dependent on posture and occasional local constriction of venous flow.
They responded poorly to digitoxin and diuretics and may therefore also be considered as having a peripheral genesis.

The significance of the similarity of the patients and the other clinical features is unclear. It seems likely, however, that the lack of vascular autoregulation with hyperkinetic circulation and heart enlargement, the clinical features and the persistent ductus, all should be viewed as parallel phenomena, acquired or genetic.

\section{References}

Bloomfeld, D. K. (1964). The natural history of ventricular septal defect in patients surviving infancy. Circulation, 29, 914 .

Boone, J. A., and Rosemond, R. M. (1960). Coincidence of patent ductus arteriosus and rheumatic heart disease, with a comment on the 'postcommissurotomy syndrome'. American fournal of Medicine, 28, 247.

Brachfeld, N., and Gorlin, R. (1960). Idiopathic hyperkinetic state: a new clinical syndrome. British Heart fournal, 22, 353.

Davies, H., Oliver, G. C., Rappoport, W. J., and Gazetopoulos, N. (1970). Abnormal left heart function after operation for atrial septal defect. British Heart fournal, 32, 747.

Dunlop, D., and Shanks, R. G. (1968). Selective blockade of adrenoceptive beta receptors in the heart. British fournal of Pharmacology and Chemotherapy, 32, 201.

Ekström, G. (1952). The surgical treatment of patent ductus arteriosus. Acta Chirurgica Scandinavica, Suppl. 169.

Frohlich, E. D., Dustan, H. P., and Page, I. H. (I966). Hyperdynamic beta-adrenergic circulatory state. Archives of Internal Medicine, 117, 614.

Frohlich, E. D., Tarazi, R. C., and Dustan, H. P. (1969). Hyperdynamic beta-adrenergic circulatory state: increased beta-receptor responsiveness. Archives of Internal Medicine, 123, $\mathrm{I}$.

Gorlin, R. (1962). The hyperkinetic heart syndrome. fournal of the American Medical Association, 182, 823.

Guyton, A. C., Granger, H. J., and Coleman, T. G. (I97I). Autoregulation of the total systemic circulation and its relation to control of cardiac output and arterial pressure. Circulation Research, 28, Suppl. I, 93.

Helsingen, N., Husom, O., and Efskind, L. (1958). A follow-up study of 250 patients subjected to surgical treatment of patent ductus arteriosus. Thorax, 13, 210.

Holmgren, A., Jonsson, B., Levander, M., Linderholm, H., Sjöstrand, T., and Ström, G. (1957). Low physical working capacity in suspected heart cases due to inadequate adjustment of peripheral blood flow (vasoregulatory asthenia). Acta Medica Scandinavica, 158, 413.

Jarmakani, M. M., Graham, T. P., Canent, R. V., Spach, M. S., and Capp, M. P. (1969). Effect of site of shunt on left heart-volume characteristics in children with ventricular septal defect and patent ductus arteriosus. Circulation, 40, 4I I.

Lueker, R. D., Vogel, J. H. K., and Blount, S. G. (1969). Cardiovascular abnormalities following surgery for left-to-right shunts. Circulation, 40, 785 . 
Mason, D. T., Zelis, R., Spann, J. F., and Braunwald, E. (1968). Alterations of left ventricular performance and myocardial mechanics in patent ductus arteriosus and ventricular septal defect. Clinical Research, 16, 240.

Strauss, P., Abrams, H. L., and Robinson, S. (1958). Radiologic aspects of operable heart disease. VI. Changes following surgical closure of patent ductus arteriosus. Circulation, 17, 1047.
Trippestad, A., and Efskind, L. (1972). Patent ductus arteriosus. Surgical treatment of 686 patients. Scandinavian fournal of Thoracic and Cardiovascular Surgery, 6, 38.

Requests for reprints to Dr. Knut Rasmussen, Medical Department B, University Hospital, Rikshospitalet, Oslo, Norway. 